\title{
Proposiciones Aprobadas en la Primera Convención Nacional de Obstetricia y Ginecología
}

\author{
Proposición del Dr. Rafael Peralta C.:
}

"La Convención Nacional de Obstetricia y Ginecologia" nombrará una comisión compuesta por siete miembros, encargada de elaborar las conclusiones de esta Primera Convención. (Fdos.): Rafael Peralta C., Carlos Martínez Sáenz, Rodulfo Camero Castaño, Hernando Navas Angel.

La anterior proposición es aprobada por unanimidad y la Convención por intermedio de la Mesa Directiva, nombra para integrar la comisión de Conclusiones, a los Dres. Peralta. Acosta Bendeck, Botero Peláez, Becerra, Cardona, Rey y Amaya.

\section{Propoción de los Dres. Hugo Campo y Tomás Becerra:}

"Los suscritos delegados por el Departamento del Valle a la Primera Con. vención Nacional de Obstetricia y Ginecologia, felicitan efusivamente a sus organizadores por el admirable y rotundo exito de esta reunión y los exhortan a seguir laborando en pro del engrandecimiento de dichas especialidades. (Fdos.): Hugo Campo Gaviria, Tomás Becerra García.

Aprobada por unanimidad

\section{Proposición de los Dres. Pérez, Pachón y Sanz:}

"Adiciónese a las Conclusiones de la Primera Convención Nacional de Obstetricia y Ginecologia, el respaldo total a los puntos de vista que la Federa. ción Médica Colombiana ha expuesto al señor Presidente de la República, sobre la inmigración de médicos extranjeros". (Fdos.): Dres. Eugenio Pérez Gómez. Agustin Pachón. Mario Sanz Araos.

\section{Propoctsión presentada por la Mesa Directiva de la SCOG.:}

a) Todos los Obstetras y Ginecólogos asistentes a la Primera Convención Na. cional de Obstetricia y Ginecologia, que hasta el momento no pertenczcan a la Sociedad Colombin de Obstetricia y Ginecologia. seran considerados en adelante como MIEMBROS CORRESPONDIENTES de ella. 
b) Los miembros afiliados de la SCOG., que hayan presentado trabajos en la Convención pasarán de hecho a ser MIEMBROS DE NUMERO.

c) Los internos de las especialidades obstétrica y ginecológica que hayan colaborado en los trabajos presentados, serán de hecho MIEMBROS AFILIADOS Aprobada por unanimidad.

Proposición presentada por el Dr. José M. Garrido Gómez, de la Delegación del Atlántico:

"La Primera Convención Nacional de Ostetricia y Ginecología rinde un emocionado homenaje a la Mujer Colombiana por su abnegada labor social y como a ella atañen principalmente sus actividades cientificas, excita a los poderes publicos a preocuparse seriamente por una debida protección en su salud, obli. gaciones y derechos para bienestar del hogar colombiano.

\section{Proposición de la Mesa Directiva de la SCOG.:}

La Primera Convención Nacional de Obstetricia y Ginecologia, presenta una moción de gratitud a los Laboratorios Farmacológicos y a las casas de equipos médicos que colaboraron en este certamen.

Despedida del Presidente da la SCOG.

1 p. m. Almuerzo ofrecido por la SCOG. en el Hotel Tequendama. 